\title{
COLHEITA MECÂNICA DA CANA-DE-AÇÚCAR: ALGUNS PARÂMETROS
}

TOIGO, Roberto José ${ }^{1}$

CASAGRANDE, Marcos Virgílioº

Recebido em: 2008-09-25

Aprovado em: 2009-03-09

ISSUE DOI: $10.3738 / 1982.2278 .144$

RESUMO: A mecanização da colheita da cana-de-açúcar é uma tecnologia que vem facilitando o corte, a secção, a limpeza e o carregamento dos colmos. Este artigo evidencia os principais parâmetros que interferem na adoção do processo de mecanização da colheita da cultura da cana-de-açúcar no Brasil. Com base em referencial teórico, analisam-se alguns parâmetros envolvidos no processo de colheita mecânica da cana-de-açúcar, tais como: variedades adaptáveis à mecanização, máquinas eficientes e precisas, mão-de-obra especializada para absorver os avanços tecnológicos, que propiciam uma melhor qualidade da matéria-prima fornecida para a indústria.

Palavras-chave: Cana-de-açúcar. Colheita mecanizada. Parâmetros. Variedades. Máquinas. Operadores.

\section{SUGARCANE MECHANICAL HARVESTING: SOME PARAMETERS}

SUMMARY: The harvesting mechanization of sugar cane is a technology which has facilitated the cut, the section, the cleaning and the loading of the stalks. This article analyses the main parameters that interferes in adopting the process of mechanical harvesting in sugarcane crop in Brazil. Based on theoretical references, some parameters engaged in the process of mechanical harvesting of sugarcane were analyzed, such as: adaptable varieties for mechanization, efficient and precise machines, specialized laboring to absorb all technological improvements which make practical a better quality of the raw material supplied for the industry.

Keywords: Sugarcane. Mechanical harvesting. Parameters. Varieties. Machines. Operators.

\section{INTRODUÇÃO}

A cana-de-açúcar (Saccharum spp.) tem sido considerada como uma das melhores opções entre as fontes renováveis de energia, evidenciando-se como uma cultura de grande importância no mercado agrícola brasileiro e muito promissora no âmbito mundial (MILAN, 1999). A cultura tem sido bastante utilizada no Brasil in natura, como forragem, como fonte de açúcar e melado e atualmente, em maior escala, para obtenção de álcool combustível. Além

1 Eng. Agrônomo, pela Universidade de Rio Verde-GO (Fesurv) e Esp. em Gestão e Tecnologia Sulcroalcooleira pela Faculdade "Dr. Francisco Maeda".

2 Eng. Agrônomo pela Escola Superior de Agricultura "Luiz de Queiroz" - ESALQ-USP; Mestre em Fitopatologia pela Escola Superior de Agricultura "Luiz de Queiroz" - ESALQ-USP; Líder de Produto no Centro de Tecnologia Canavieira - CTC. 
disso, outra importante contribuição à matriz energética nacional é o aproveitamento do bagaço de cana-de-açúcar para a co-geração de energia (NEVES et al., 2003; SILVA, 2007).

A grande expansão das lavouras de cana-de-açúcar no território brasileiro tem propiciado um rápido crescimento em vários segmentos produtivos, com destaque para os insumos, máquinas, equipamentos, além da grande ocupação da mão-de-obra direta ou indiretamente (SEGOVIA, 2004). Em função das grandes áreas ocupadas pela cultura e da forte expansão prevista para os próximos anos, estima-se um aumento significativo na mecanização da lavoura, a exemplo do que acontece com outras culturas de grande porte, como a soja. A mecanização do plantio e principalmente da colheita da cana-de-açúcar tem sido motivada pela falta e elevado custo da mão-de-obra, pela pressão dos custos de produção, e também para atender a legislação vigente, que prevê o fim das queimadas dos canaviais antes da colheita.

A colheita mecanizada foi iniciada a partir da década de 1940 em função da escassez de mão-de-obra. Inicialmente as máquinas colhiam as canas inteiras, deixando-as prontas para serem carregadas em montes de 750 a $1000 \mathrm{~kg}$. Com a evolução das colhedoras, lançou-se na década de 1970 a primeira colhedora $(\mathrm{CH} 200)$ de cana picada, com a principal vantagem de otimizar o transporte, unindo as operações de colheita e transbordo.

A introdução da colheita mecanizada no Brasil teve inicio na década de 1970, mudando completamente o conceito da colheita de cana-de-açúcar, com a utilização de equipamentos de fabricação nacional a partir de tecnologia importada de outros países (RIPOLI; VILLANOVA, 1992).

Acolheita mecanizada já é uma realidade nas principais empresas do setor sucroalcooleiro. Ela propicia o corte, a secção, a limpeza e o carregamento dos colmos da cana-de-açúcar, em um processo totalmente integrado que agiliza a chegada da matéria-prima à indústria, reduzindo as perdas de qualidade do produto (MAGALHÃES; BRAUNBECK, 1998).

A intenção do setor sucroalcooleiro é tornar a colheita da cana-de-açúcar inteiramente mecanizada. Na Região Sudeste do Brasil, 40\% dos canaviais é colhido mecanicamente, embora haja grandes variações desse valor entre as empresas agrícolas. Aquelas que estão com as menores taxas de colheita mecanizada são as instaladas em regiões onde o relevo é mais acidentado, dificultando ou mesmo inviabilizando a mecanização. As novas unidades produtoras instaladas principalmente nos Estados do Mato Grosso, Mato Grosso do Sul e Goiás estão plantando seus canaviais em regiões de planície onde a mecanização é totalmente viável.

Neste processo de intensa mecanização é necessário que haja um estudo em relação às variedades de cana-de-açúcar que serão utilizadas pelas empresas, além do investimento em tecnologia relativo às máquinas e a conseqüente formação de mão-de-obra especializada.

Em relação às variedades, todos os programas de melhoramento genético da cana-deaçúcar do Brasil têm buscado aliar em seus cultivares o aumento de produtividade e a aptidão para a mecanização do plantio e da colheita. Exemplos desses programas podem ser observados no âmbito governamental: Programa Cana - IAC e também na iniciativa privada: CTC - Centro de Tecnologia Canavieira. Esses centros de desenvolvimento de variedades estão focados na 
atual e crescente necessidade de os novos cultivares estarem adaptados à mecanização.

Em face ao exposto, a presente pesquisa visa evidenciar os principais parâmetros que interferem na adoção do processo de mecanização da cultura da cana-de-açúcar no Brasil, a saber: variedades aptas à mecanização, máquinas ágeis e precisas, e mão-de-obra especializada para absorver e se beneficiar dos avanços tecnológicos obtidos, melhorando a qualidade da matéria prima fornecida para a indústria.

\section{ALGUNS PARÂMETROS ENVOLVIDOS NA COLHEITA MECANIZADA}

\section{VARIEDADES}

A crescente demanda brasileira pelo álcool combustível tem sido motivada pelos constantes aumentos do petróleo com reflexos imediatos no preço da gasolina. Some-se a isso o fato do país ter desenvolvido a tecnologia dos motores bicombustíveis, que permite aos consumidores escolher o tipo de combustível que irão usar: álcool e/ou gasolina. Maiores demandas pelo álcool implicam em maior produção do combustível, que por sua vez requer maiores quantidades de matéria-prima: a cana-de-açúcar. Neste contexto, os programas de melhoramento genético da gramínea têm tido papel fundamental ao desenvolver variedades mais produtivas. Anualmente, novas variedades são lançadas no mercado prometendo maiores produtividades e melhor adaptação à mecanização. No presente, as principais siglas de variedades no Brasil são: CTC (Centro de Tecnologia Canavieira), IAC (Instituto Agronômico de Campinas) e RB (Ridesa). Atualmente, os produtores podem contar com mais de 50 cultivares produzidos pelo três centros, tornando mais complexa a decisão pelo plantel varietal mais adequado às suas necessidades edafoclimáticas e de manejo. A escolha das variedades de cana-de-açúcar que serão cultivadas é de suma importância para o produtor, sendo assim, ele deverá estar atento a um conjunto de características que serão fundamentais para a produtividade dos seus canaviais, tais como: maior produção por unidade de área, melhor adaptação à região de cultivo, melhores características agroindustriais, resistência a doenças e pragas, e, obviamente, aptidão à colheita mecanizada.

De acordo com Landell et al. (2006) algumas características das variedades devem ser observadas para verificar seu desempenho em relação à região de cultivo escolhida, a saber: as condições climáticas do local, o comportamento de cada variedade a ser cultivada e as características do solo na região de cultivo (textura, fertilidade, CTC do horizonte A, retenção de cátions, teor de água, etc.). As características edafoclimáticas da região de cultivo serão determinantes para a escolha das variedades que irão compor os canaviais da empresa, bem como para a determinação da melhor época para a colheita das plantas, visando não comprometer o potencial produtivo e qualitativo da cultura. Vale lembrar a importância da diversificação das variedades para o cultivo a fim de minimizar os riscos inerentes aos ataques de doenças e pragas. Epidemias de doenças como o carvão e o mosaico, observadas no passado, servem para 
alertar sobre o risco potencial que as empresas correm ao basear sua fonte de matéria prima em poucas variedades. Em relação a isso se sugere que uma variedade, por melhor que seja, jamais ocupe mais do que $20 \%$ dos canaviais de uma empresa. Neste contexto, a grande oferta de variedades atualmente no mercado serve para minimizar os riscos de epidemias, uma vez que a base genética das plantas é mais diversificada. Para se ter uma idéia da situação, em 1984, a introdução de uma nova doença à qual a variedade NA56-79 (principal variedade na época) fosse suscetível teria o potencial de destruir $42 \%$ da lavoura nacional. Já em 2003, a introdução de uma nova doença que afetasse a principal variedade poderia prejudicar apenas $15 \%$ dos canaviais (informação verbal) ${ }^{3}$.

Em relação à aptidão para a colheita mecanizada, um cultivar de cana-de-açúcar deverá apresentar algumas características fenotípicas desejáveis, entre as quais se destaca o porte ereto, a resistência ao corte mecânico, para que não haja abalo da planta e a despalha natural. Essas características são importantes para facilitar a operacionalização no campo e devem ser consideradas no momento de se planejar o plantel varietal que será adotado pela empresa. Além dos fatores citados, a curva de maturação das variedades e o período útil de industrialização das mesmas também são fundamentais para a escolha das variedades, visando garantir um bom padrão de maturação em toda a área colhida (PEREIRA; TORREZAN, 2006).

\section{MÁQUINAS}

A utilização de colhedoras mecanizadas tem sido mais freqüente nos diferentes sistemas de produção agroindustriais (NEVES et al., 2003). Na cultura de cana-de-açúcar cerca de 30\% das lavouras é colhida por máquinas (PEARCE, 2006). Segundo Ripoli e Ripoli (2004), existem dois tipos de máquinas, as colhedoras de cana inteira e as colhedoras de cana picada, sendo que a maioria dos produtores opta pelo segundo tipo devido à sua maior eficiência no sistema de corte, carregamento e transporte.

Segundo Magalhães e Braunbeck (1998), é crescente o interesse pela colheita de canade-açúcar com colhedoras de cana picada, sobretudo em locais onde a topografia é adequada à atividade e ocorre escassez de mão-de-obra. Essas máquinas cortam, picam, limpam e carregam a cana-de-açúcar em operações integradas.

Para que todos esses processos ocorram com sucesso deve-se observar algumas características que tornarão a colheita mais eficiente. Segundo Pereira e Torrezan (2006) é importante observar os seguintes parâmetros:

$\Rightarrow$ Verificar o tipo de máquina que será utilizada na colheita para determinar o espaçamento ideal a ser implantado na lavoura, pois assim o espaçamento estará adequado à passagem da esteira ou do pneu da colhedora, evitando o pisoteio das plantas e propiciando uma melhor brotação da cana soca;

$\Rightarrow$ Efetuar um completo arranjo na área de plantio, eliminando todas as irregularidades

3 Informação fornecida pelo prof. Dr. Marcos Vírgilio Casagrande.

Nucleus, v.6, n.1, abr. 2009 
existentes no terreno, como sulcos, barrancos e buracos, além de detectar o grau de compactação do solo e sua profundidade (principalmente em áreas de reforma);

$\Rightarrow$ Promover o nivelamento do terreno, realizando uma operação conhecida como "quebra lombo" para facilitar o corte na base dos colmos sem que as lâminas da colhedora tenham contato com o solo. Assim, ocorrerá uma significativa redução no grau de impurezas minerais e vegetais transportadas para a indústria juntamente com a matéria prima, reduzindo as perdas industriais;

$\Rightarrow$ Escolher variedades mais aptas à mecanização, com características tais como o porte ereto para facilitar o corte basal e de ponteiras; a resistência ao corte, para que não ocorra o abalo do sistema radicular das plantas durante o processo, garantindo a rebrota; e a despalha natural facilitando a limpeza e diminuindo o grau de impurezas vegetais na indústria;

$\Rightarrow$ Observar a declividade do terreno, sendo que para as colhedoras de esteira a mesma não deverá ser superior a $14 \%$ e para colhedoras de pneu poderá ser no máximo de $18 \%$, evitando possíveis acidentes;

$\Rightarrow$ Delinear os talhões e carreadores dos canaviais de acordo com a declividade do terreno, maximizando o aspecto operacional, principalmente com a utilização de transbordos e evitando perdas de tempo com manobras excessivas.

Além de permitir a padronização do início do processamento da matéria-prima, a colheita mecânica da cana-de-açúcar também propicia uma maior segurança no processo produtivo, melhorando significativamente o controle das atividades de corte e sua compatibilização com o ritmo da indústria, diminuindo os problemas ambientais causados pela queima dos canaviais, reduzindo a instabilidade da mão-de-obra e aumentando significativamente a área colhida (USTULIN; SEVERO, 2008).

A mecanização da colheita da cana é um fato inevitável e todas as modificações relativas ao corte não se resumem a uma simples substituição de um procedimento por outro. Na verdade, trata-se da combinação do preparo do solo na lavoura com a estruturação de novos equipamentos no campo, envolvendo toda a equipe que auxilia o processo desde o corte até recepção da matéria-prima pela indústria (RODRIGUES; SAAB, 2007).

É importante considerar que a adoção de colhedoras por parte dos empresários do setor agroindustrial deve ser considerada como uma prática fundamental para a modernização da agricultura (VEIGA FILHO, 1994). A partir desta ampla modernização do setor, com inovações tecnológicas para o corte da cana-de-açúcar, verifica-se que o trabalhador braçal se extingue e surge o operador da colhedora, que precisa estar qualificado e bem treinado para este mercado preciso e exigente.

\section{OPERADOR}

Com o processo da mecanização na cultura da cana-de-açúcar, tem-se observado que esta nova realidade exige do operador da colhedora uma nova postura frente ao seu posto e ao 
exercício de sua função. As várias e constantes modificações dos equipamentos exigem um grande grau de conhecimento e adaptabilidade, e ao mesmo tempo proporcionam maiores graus de conforto e segurança no trabalho (SILVA, 2007).

Para que o operador realize bem a sua função na condução das colhedoras mecânicas é necessário observar alguns parâmetros que são fundamentais para que a colheita se desenvolva da melhor maneira possível, a saber:

$\Rightarrow$ Total conhecimento técnico e funcional da máquina, assim o operador saberá lidar com qualquer eventualidade, distinguindo as funções dos sistemas técnicos contidos na mesma. Entre essas funções estão a regulagem do assento, os sistemas de controle de clima, os sistemas de comunicações, etc. (SKOGFORSK, 1999);

$\Rightarrow$ Conhecimento técnico do posicionamento do corte dos ponteiros, pois é o operador quem define a posição do corte, visando reduzir o índice de impurezas vegetais levadas para a indústria. Da mesma forma, deverá saber como conduzir o corte de base dos colmos que não deverá ultrapassar a altura de 100 mm, visando não ocasionar problemas nas socas;

$\Rightarrow$ Responsabilidade e disciplina são aspectos significativos para que o operador possa manusear uma máquina colhedora, principalmente em função do rodízio de profissionais que ocorre na época da colheita, o qual determina o custo operacional das horas trabalhadas.

O sucesso da colheita mecânica depende fundamentalmente do operador, por isso o mesmo deverá ser preparado para realizá-la. Uma colhedora de alta qualidade e um operador bem treinado proporcionarão maiores ganhos às empresas em função da redução das perdas nos setores agrícolas e industriais (PEREIRA; TORREZAN, 2006). Programas de qualificação profissional são essenciais para minimizar os custos e propiciar uma colheita de melhor qualidade.

\section{CONSIDERAÇÕES FINAIS}

O planejamento para a implantação da colheita mecanizada na cultura da cana-deaçúcar deve ser criterioso para minimizar as chances de erros. A não observação dos parâmetros citados poderá resultar em aumentos no custo de produção, com a conseqüente redução do lucro. A correta seleção das variedades que irão compor o plantel varietal da empresa, a escolha de máquinas mais ágeis e precisas para a realização da colheita dos canaviais e a constante qualificação dos operadores das colhedoras são fundamentais na composição do equilíbrio do sistema de colheita mecanizada na cultura da cana-de-açúcar.

\section{REFERÊNCIAS}

LANDELL, M. G. de A.et al. Manejo varietal em cana-de-açúcar. In: SEGATO, S. V.; PINTO, A. de S.; JENDIROBA, E.; NOBREGA, J. C. M. de. Atualização em produção de cana de açúcar. Piracicaba: CP 2m, 2006. p.57-65. 
MAGALHÃES, P. S. G.; BRAUNBECK, O. A colheita de cana-de-açúcar: atualidade e perspectiva. In: CONGRESO DE INGENIERÍA RURAL Y MECANIZACIÓN AGRARIA EM EL AMBITO LATINOAMERICANO. Anais... La Plata: Argentina, 1998. p.262-271.

MILAN, M. Fatores críticos no sistema de produção de cana-de-açúcar. Engenharia Agrícola, Jaboticabal, v.18, n.4, p.100-109, jun. 1999.

NEVES, J. L. M et al.. Avaliação de perdas invisíveis de cana-de-açúcar nos sistemas da colhedora de cana picada. Engenharia Agrícola, Jaboticabal, v.23, n.3, p.539-546, set./dez. 2003.

PEREIRA, L. L.; TORREZAN, H. F. Colheita mecanizada da cana-de-açúcar. In: SEGATO, S. V.; PINTO, A. de S.; JENDIROBA, E.; NOBREGA, J. C. M. de. Atualização em produção de cana de açúcar. Piracicaba: CP 2m, 2006. p.333-344.

RIPOLI, T. C. C.; RIPOLI, M. L. C. Biomassa de cana-de-açúcar: colheita, energia e ambiente. Piracicaba: USP/ESALQ, 2004. 302p.

RIPOLI, T. C. C.; VILA NOVA, N. A. Colheita mecanizada de cana-de-açúcar: novos desafios. Revista STAB, Piracicaba, v.11, n.1, p.28-31, set./out. 1992.

RODRIGUES, E. B.; SAAB, O. J. G. A. Avaliação técnico-econômica da colheita manual e mecanizada da cana-de-açúcar (saccharum spp) na região de Bandeirantes-Pr. Semina: Ciências Agrárias, Londrina, v.28, n.4, p.581-588, out./dez. 2007.

SEGOVIA, N. V. M. Perfil tecnológico dos fornecedores de cana-de-açúcar e entraves para a adoção de sistemas agroflorestais na região de Piracicaba, SP - Brasil. 2004. 103f. Dissertação (Mestrado em Fitotecnia) - Escola Superior de Agricultura "Luiz de Queiroz", Piracicaba.

SILVA, C. B. da. Perfil antropométrico de operadores e avaliação ergonômica de colhedoras de cana-de-açúcar. 2007. 91f. Tese (Doutorado em Fitotecnia) - Universidade Federal de Lavras.

SKOGFORSK. The forestry research institurte of sweden. Ergonomic guidelines for Forest machines. Uppsala, Sweden: Swedish National Institute for Working Life, 1999. 86p.

USTULIN, E. J.; SEVERO, J. R. Cana-de-açúcar: proteger o ambiente e continuar gerando empregos. Disponível em: $<$ http://www.cna.org.br/site/noticia.php?ag=0\&n=1172>. Acesso em: 18/04/2008.

VEIGA FILHO, A. A. Análise da mecanização do corte da cana-de-açúcar no Estado de São Paulo. Informações Econômicas, São Paulo, v.24, n.10, p.44-59, out.1994. 